\title{
Radioisotope Electric Propulsion for Fast Outer Planetary Orbiters
}

Steven Oleson, Scott Benson, Leon Gefert, Michael Patterson, and Jeffrey Schreiber

Glenn Research Center, Cleveland, Ohio 
Since its founding, NASA has been dedicated to the advancement of aeronautics and space science. The NASA Scientific and Technical Information (STI) Program Office plays a key part in helping NASA maintain this important role.

The NASA STI Program Office is operated by Langley Research Center, the Lead Center for NASA's scientific and technical information. The NASA STI Program Office provides access to the NASA STI Database, the largest collection of aeronautical and space science STI in the world. The Program Office is also NASA's institutional mechanism for disseminating the results of its research and development activities. These results are published by NASA in the NASA STI Report Series, which includes the following report types:

- TECHNICAL PUBLICATION. Reports of completed research or a major significant phase of research that present the results of NASA programs and include extensive data or theoretical analysis. Includes compilations of significant scientific and technical data and information deemed to be of continuing reference value. NASA's counterpart of peerreviewed formal professional papers but has less stringent limitations on manuscript length and extent of graphic presentations.

- TECHNICAL MEMORANDUM. Scientific and technical findings that are preliminary or of specialized interest, e.g., quick release reports, working papers, and bibliographies that contain minimal annotation. Does not contain extensive analysis.

- CONTRACTOR REPORT. Scientific and technical findings by NASA-sponsored contractors and grantees.
- CONFERENCE PUBLICATION. Collected papers from scientific and technical conferences, symposia, seminars, or other meetings sponsored or cosponsored by NASA.

- SPECIAL PUbliCATION. Scientific, technical, or historical information from NASA programs, projects, and missions, often concerned with subjects having substantial public interest.

- TECHNICAL TRANSLATION. Englishlanguage translations of foreign scientific and technical material pertinent to NASA's mission.

Specialized services that complement the STI Program Office's diverse offerings include creating custom thesauri, building customized databases, organizing and publishing research results ... even providing videos.

For more information about the NASA STI Program Office, see the following:

- Access the NASA STI Program Home Page at http://www.sti.nasa.gov

- E-mail your question via the Internet to help@sti.nasa.gov

- Fax your question to the NASA Access Help Desk at 301-621-0134

- Telephone the NASA Access Help Desk at 301-621-0390

- Write to: NASA Access Help Desk NASA Center for AeroSpace Information 7121 Standard Drive Hanover, MD 21076 


\section{Radioisotope Electric Propulsion for Fast Outer Planetary Orbiters}

Steven Oleson, Scott Benson, Leon Gefert, Michael Patterson, and Jeffrey Schreiber

Glenn Research Center, Cleveland, Ohio

Prepared for the

38th Joint Propulsion Conference and Exhibit

cosponsored by the AIAA, ASME, SAE, and ASEE

Indianapolis, Indiana, July 7-10, 2002

National Aeronautics and

Space Administration

Glenn Research Center 


\section{Acknowledgments}

The authors wish to thank Dr. Robert Noble for his previous work on and enthusiasm for the radioisotope electric propulsion concept. The authors are also indebted to Leonard Dudzinski, John Riehl, and Glen Horvat for their assistance in running the VARITOP program and developing this concept.

Trade names or manufacturers' names are used in this report for identification only. This usage does not constitute an official endorsement, either expressed or implied, by the National Aeronautics and Space Administration.

Available from

NASA Center for Aerospace Information

7121 Standard Drive

Hanover, MD 21076
National Technical Information Service 5285 Port Royal Road Springfield, VA 22100 


\title{
RADIOISOTOPE ELECTRIC PROPULSION FOR FAST OUTER PLANETARY ORBITERS
}

\author{
Steven Oleson, Scott Benson, Leon Gefert, Michael Patterson, and Jeffrey Schreiber \\ National Aeronautics and Space Administration \\ Glenn Research Center \\ Cleveland, Ohio \\ Contact: Steve Olesonerenasa.gov
}

\begin{abstract}
Recent interest in outer planetary targets by the Office of Space Science has spurred the search for technology options to enable relatively quick missions to outer planetary targets. Several options are being explored including solar electric propelled stages combined with aerocapture at the target and nuclear electric propulsion. Another option uses radioisotope powered electric thrusters to reach the outer planets. Past work looked at using this technology to provide faster flybys. A better use for this technology is for outer planet orbiters. Combined with medium class launch vehicles and a new direct trajectory these small, sub-kilowatt ion thrusters and Stirling radioisotope generators were found to allow missions as fast as 5 to 12 years for objects from Saturn to Pluto, respectively. Key to the development is light spacecraft and science payload technologies.
\end{abstract}

\section{Introduction}

Outer planet exploration has experienced new interest with the open competition and award for a Pluto flyby mission. Voyager 2 conducted flybys of all the outer planets from Jupiter outward, except for Pluto, giving us a short glimpse of these mysterious planets and their many moons. In 2000, at the request of the NASA Deep Space Exploration Technology Program, an examination of advanced power and propulsion technologies to allow a post-2004 launch of a fast Pluto flyby (missing the 2004 launched Jupiter gravity assist opportunity) was undertaken at Glenn Research Center (GRC). It was found that with the use of small, advanced 8 $\mathrm{cm}$ ion thrusters and Stirling radioisotope generators (SRG), both under development at GRC, it was possible to deliver the Pluto/Kuiper flyby spacecraft in 7 to 12 years without the need of a Jupiter gravity assist. ${ }^{1}$ With the promising results of this analysis, a look at other missions to other planetary objects using this concept was recently undertaken. Besides the outer planets and their moons many other targets of scientific interest exist including the Jupiter Trojans, the
Centaurs, other asteroids, comets, and TransNeptunian objects. ${ }^{1,2}$

In several past works, Robert Noble of Fermi labs has noted the potential advantages of using radioisotope-powered ion propulsion for outer planet exploration. ${ }^{3,4,5}$ Advantages of radioisotope electric propulsion (REP) include a long-life power source, not reliant on the sun, which provides propulsion power to reach the target and then provides relatively high power levels for science payloads (since more power is needed for the ion propulsion system as opposed to past all chemical radioisotope powered spacecraft). REP also provides a propulsion system which uses much less fuel than chemical systems and therefore allows the use of smaller launch vehicles. The primary disadvantage to the REP system is its limited propulsion power, (hundreds of watts), which limits the reasonable payload spacecraft size (without power or propulsion) to around 100 to $300 \mathrm{~kg}$ for REP missions of reasonable duration. If larger payloads are required a nuclear reactor powered system would be needed. 
While the past studies noted the advantages of combining radioisotope and ion propulsion technologies, the technologies to provide a lightweight power and propulsion system did not exist. Specific masses of 100 to $150 \mathrm{~kg} / \mathrm{kW}$ are needed to provide reasonable mission times and performance. Existing radioisotope thermoelectric generators (RTGs) combined with off- the-shelf ion propulsion systems (e.g. the 30 $\mathrm{cm}$ Ion propulsion system flown on Deep Space 1 and capable of $500 \mathrm{~W}$ operation) would provide a combined specific mass of almost 300 $\mathrm{kg} / \mathrm{kW}$. Current RTGs also use many more plutonium bricks due to the low efficiency of the thermoelectric conversion system. Use of the Stirling convertor promises an almost four-fold improvement in electric conversion efficiency, thus reducing the number of required plutonium bricks by the same factor. Long life, low power ion propulsion is also needed to reduce the thruster system mass required for the extended burn times.

The final requirement to make the REP concept feasible is a small but capable spacecraft, with science package, but not including power and propulsion, of around 100 to $300 \mathrm{~kg}$. While the technologies needed for an light-weight REP spacecraft are still under evaluation the potential mission opportunities for such a spacecraft are explored in this work.

Past works looked at using small launch vehicles (Delta II Class) to launch these REP orbiters. ${ }^{1}$ Trip times were estimated to be as long as 24 years (Pluto Orbiter). New work has discovered that using a medium class launch vehicle with an upper stage can reduce the REP trip times $50 \%$. This is achieved by using the launch vehicle to provide the Earth escape and acceleration while the REP (generally) only has to decelerate the vehicle.

\section{$\underline{\text { REP Technologies }}$}

The three key technologies needed for an REP spacecraft are small, advanced ion thrusters, lightweight radioisotope power systems, and small spacecraft which can perform valuable science. This scoping study assumed ion thrusters with an operational power range of 100$500 \mathrm{~W}$, Stirling radioisotope generators that can supply constant power of $100-900 \mathrm{~W}$ to the ion propulsion system and lightweight spacecraft bus technologies that enable revolutionary 100-300 $\mathrm{kg}$ spacecraft bus designs. Each will be discussed in turn.

\section{Sub-kilowatt Ion Propulsion}

NASA Glenn Research Center is developing a lightweight $(<3.0 \mathrm{~kg}$ combined mass, representing a $80 \%$ reduction from state-of-theart), sub-kilowatt thruster (figure 1) and power processor. Performance goals include 50\% efficiency at $0.25 \mathrm{~kW}$, representing a $2 \mathrm{x}$ increase over the state-of-the-art.

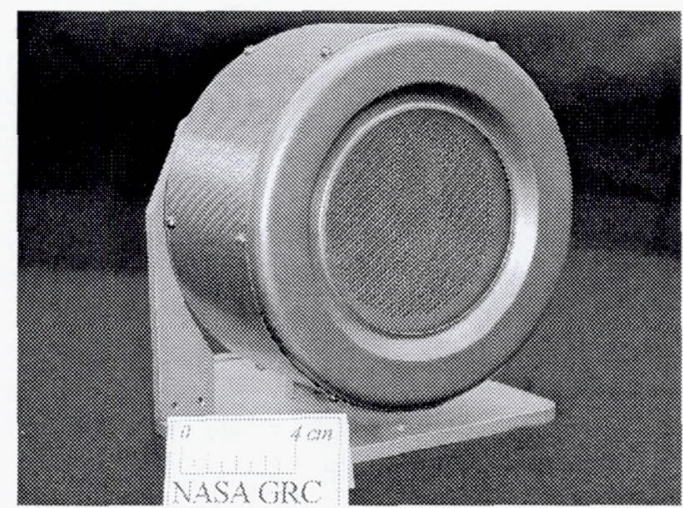

Figure 1. NASA $8 \mathrm{~cm}$ Ion Thruster

The sub-kilowatt ion propulsion activity includes both an in-house hardware development element for the thruster and power processor, as well as a contracted system element. At NASA GRC, the fabrication and performance assessment of a small $(0.25 \mathrm{~kW}$ class $)$ laboratory model thruster with an $8 \mathrm{~cm}$ beam diameter has been completed, ${ }^{6-9}$ and the fabrication of a secondgeneration lightweight engineering model thruster with a 100-500 W power throttling envelope has also been completed. Also at NASA GRC, first- and second-generation breadboard power processors have been fabricated and successfully integrated with the 8 cm thruster. ${ }^{10-12}$

The second-generation breadboard power processing unit (PPU) (Figure 2) was fabricated with a maximum output power capability of up to $0.45 \mathrm{~kW}$ at a total efficiency of up to 90 percent. Four power converters were used to produce the required six electrical outputs which resulted in significant mass reduction for the 
PPU. The component mass of this breadboard is $0.65 \mathrm{~kg}$ and the total power convertor mass is 1.9 $\mathrm{kg}$. Integration tests with the thruster included short circuit survivability, single and continuous recycle sequencing, and beam current closedloop regulation.

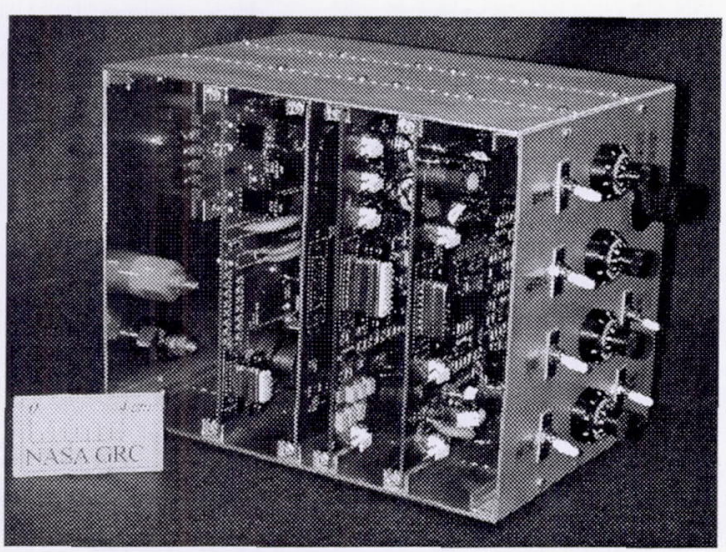

Figure 2. Power Processing Unit

General Dynamics, under contract, developed a conceptual design for the low-power ion propulsion system. ${ }^{13}$ The objectives of this effort were to develop a system that improved performance and reduced system mass compared to existing state-of-the-art systems. The resulting design was tailored to the meet the needs of the satellite and spacecraft integration community as identified in an extensive user survey performed by General Dynamics. The basic characteristics of the system are as follows:

\author{
up to $20 \mathrm{mN}$ thrust \\ 100-500 Watts input power \\ 1600-3500 seconds Isp \\ thruster mass: $0.95 \mathrm{~kg}$ \\ PPU mass: $2.0 \mathrm{~kg}$
}

Central Xenon Feed System mass: $3.1 \mathrm{~kg}$ (excluding tank)

Recently, an $8 \mathrm{~cm}$ pyrolitic graphite grid set was tested at GRC. Initial results showed operational performance similar to that of molybdenum grids. ${ }^{14}$ Lifetime estimates using such materials predicts improvements over molybdenum of a factor of 5 or more.

\section{Stirling Radioisotope Generator}

An advanced radioisotope electric power generator is currently being developed for use on deep space missions, as well as for Mars surface applications. It is based on the high efficiency free-piston Stirling power convertor (Stirling engine coupled to a linear alternator). The Department of Energy (DOE) has responsibility for developing the SRG for use on NASA missions. GRC is supporting DOE in this effort, drawing upon its many years of experience in developing Stirling power conversion technology. The SRG is a high-efficiency alternative to the Radioisotope Thermoelectric Generators (RTGs) that have been used to power past missions. The Stirling efficiency, in excess of $25 \%$, leads to a factor of 4 reduction in the inventory of plutonium required to heat the generator. The spacecraft power system will be comprised of one or more generators, based on the power requirements of the mission.

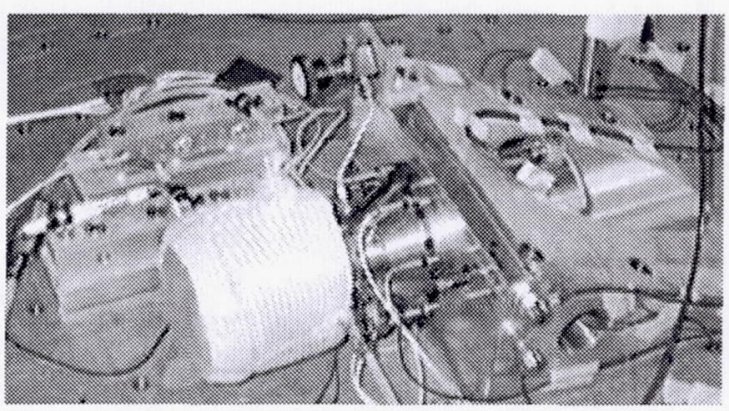

Figure 3. Stirling Technology
Demonstrator Convertor

The SRG will be based on a Stirling power convertor known as the Technology Demonstration Convertor (TDC). The TDC was developed as a laboratory device to validate freepiston Stirling technology for the radioisotope generator application (figure 4.) A joint government/industry committee developed a set of criteria that was used to determine the readiness of Stirling technology for transition to flight. ${ }^{15}$ Having successfully passed these tests, the TDC is now being transitioned from a laboratory device to flight application. As a part

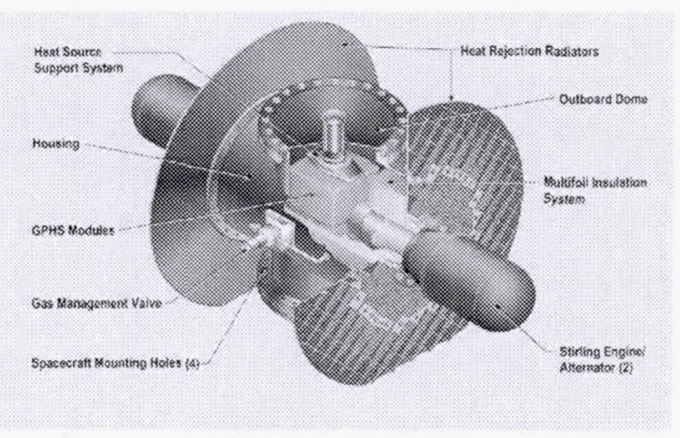

Figure 4. Stirling Radioisotope

Generator Concept 
of this process, DOE conducted a competitive procurement for a System Integration Contractor to design, develop, qualify and supply SRG units to NASA for the future missions. Lockheed Martin Aeronautics of Valley Forge, PA was selected as the System Integration Contractor. Figure 4 shows an early concept of the SRG however the unit being developed differs significantly from this. The present schedule would produce an engineering unit in about two years. The follow-on effort would produce a qual unit and then flight units for missions in the later half of the decade.

The SRG will be heated by plutonium housed inside of two General Purpose Heat Source modules. Each module will provide approximately $250 \mathrm{~W}_{\text {th }}$ at beginning of mission (BOM). The initial SRG, based on the laboratory TDC transitioned to flight, will have a mass of about $27 \mathrm{~kg}$ with contingency and produce approximately $114 \mathrm{Wdc}$. This results in specific power of $4.2 \mathrm{~W} / \mathrm{kg}$. Analysis performed at GRC projects that an advanced SRG could increase the specific power to nearly $10 \mathrm{~W} / \mathrm{kg}$ with the major advance being in a low mass Stirling convertor along with modest advances in the controller and thermal systems.

Long life with no degradation has been accomplished through the use of non-contacting operation to virtually eliminate wear of the moving components. The present design of the Stirling convertor for the SRG has been designed for a 100,000 hour life (11.4 year) however the life could be extended through a design modification of the heater head or possibly through the operating methodology chosen. Three components are critical to achieving long life; the flexure bearing system, the permanent magnets in the linear alternator, and the heater head. Although the flexure technology has its origins in engines, it has gained more widespread acceptance for long-life cryocoolers. Long-life Stirling cryocoolers are presently flying on spacecraft, with the most recent launch being the RHESSI spacecraft. Flexures are designed and qualified for the design life, and are then operated at significantly derated conditions to achieve essentially infinite life. For the SRG, creep of the heater head is the life-limiting component. The life can be extended multifold by an engineering trade to reduce heater head stress and creep rate with in exchange for reduced performance. These issues are presently being addressed with analysis and tests at
GRC. ${ }^{16}$ As demonstration of the long-life capability, a free-piston Stirling convertor continues to operate after approximately 70,000 hours ( 8.0 years) with no degradation. ${ }^{17}$

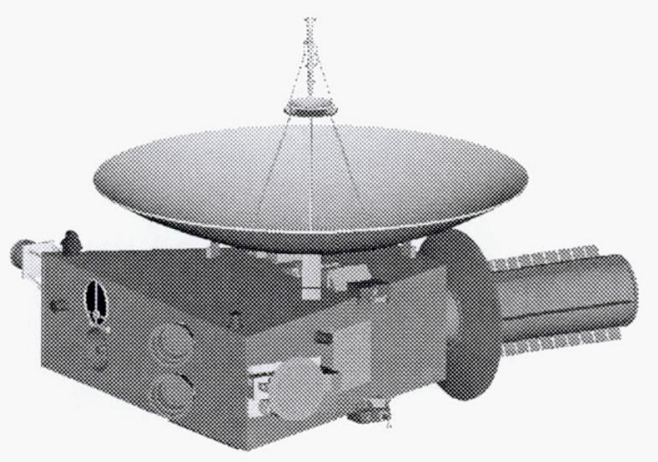

Figure 5. New Horizons Spacecraft

Lightweight Spacecraft Bus and Science Instrument Technologies

Advanced microelectronics/lightweight spacecraft bus development has been underway at the JHU/APL and will be leveraged toward the outer planet mission opportunities. This analysis is ongoing but has not been updated from past works. ${ }^{1}$

A recent spacecraft design that is of a similar class mission to that of an REP orbiter is the New Horizons Pluto Flyby mission. It has a payload mass of only $24 \mathrm{~kg}$ with a launch mass of $412 \mathrm{~kg}$. This design represents a conservative, near-term design, and includes power and chemical propulsion. ${ }^{18}$

Since the spacecraft bus is still undefined the analyses in this work traded the delivered spacecraft bus and payload mass with the propulsion parameters and trip time. When the spacecraft \& science analysis is complete it will be integrated with this analysis.

\section{Systems Analyses}

For the sample outer planetary object missions, the previous technology descriptions were modeled for mass and performance analyses. A launch date of 2011 was chosen to allow sufficient technology advancement, but earlier or later launch dates should have similar results. The assumed performance of the power and propulsion system is shown in Table 1 . The 750 $\mathrm{W}$ point was chosen after mission analysis 
iteration. Using the information in the table a fixed specific mass (alpha) of $150 \mathrm{~kg} / \mathrm{kW}$ was assumed for the trajectory runs for this scoping study. The tankage was set to $10 \%$ of the required fuel mass. An additional 30\% contingency, commensurate with mission scoping practices, was assessed to the power and propulsion system. The rest of the spacecraft: bus, science and margin, (BSM) was varied from $120 \mathrm{~kg}$ up to $300 \mathrm{~kg}$. This BSM includes the contingencies and margins for the bus and science but not the power and propulsion system.

Table 1. Outer Planet Orbiter Assumptions

\begin{tabular}{|c|c|c|}
\hline 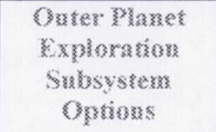 & Unit & $\begin{array}{c}\text { Total } \\
(150 \mathrm{~kg} / \mathrm{kW})\end{array}$ \\
\hline & Mass/Power & Mass/Power \\
\hline $\begin{array}{c}\text { Complete SRG } \\
\text { System }\end{array}$ & $\begin{array}{l}19 \mathrm{~kg} / \mathrm{162} \mathrm{W} \\
\text { (avg.) }\end{array}$ & $\begin{array}{c}5 \text { Units } \\
94 \mathrm{~kg} / 810 \mathrm{~W}\end{array}$ \\
\hline $\begin{array}{c}8 \mathrm{~cm} \text { Ion } \\
\text { Propulsion } \\
\text { System }\end{array}$ & & $\begin{array}{c}8 \text { Thrusters, } 3 \\
\text { PPUs } \\
18.1 \mathrm{~kg} / 750 \mathrm{~W}\end{array}$ \\
\hline $\begin{array}{c}\text { Thruster (w } \\
\text { structure, feed \& } \\
\text { gimbal) }\end{array}$ & $1.5 \mathrm{~kg}$ & \\
\hline PPUs & $2.1 \mathrm{~kg}$ & \\
\hline Feed Sys. & & $3.1 \mathrm{~kg}$ \\
\hline DCIU & $2.5 \mathrm{~kg}$ & \\
\hline $\begin{array}{l}\text { Cable (per } \\
\text { thruster) }\end{array}$ & $0.2 \mathrm{~kg}$ & \\
\hline Thermal & $0.4 \mathrm{~kg}$ & \\
\hline Tankage & $10 \%$ & \\
\hline 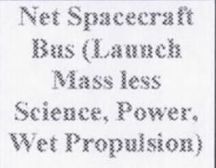 & & 100 to $300 \mathrm{keg}$ \\
\hline Sciezss & & $20-50 \mathrm{~kg}$ \\
\hline $\begin{array}{c}\text { Fuel Throughput } \\
\text { / Thruster }\end{array}$ & $20-30 \mathrm{~kg}$ xenon & \\
\hline $\begin{array}{l}\text { Ion Thruster Isp } \\
\text { (sec) }\end{array}$ & $\begin{array}{c}\text { Optimized }(2600 \mathrm{~s} \\
\text { to } 3700 \mathrm{~s})\end{array}$ & \\
\hline $\begin{array}{c}\text { Ion Propulsion } \\
\text { System } \\
\text { Efficiency }\end{array}$ & $\begin{array}{c}\text { Relative to } \\
\text { Optimal Isp } \\
(48 \% \text { to } 53 \%)\end{array}$ & \\
\hline
\end{tabular}

For the ion thruster system, lifetime was assumed possible using advanced grid technologies including thick molybdenum, titanium, or carbon based technologies (pyrolitic graphite). ${ }^{14}$ Specific impulse was optimized in the analysis to guide future development. Total propulsion system peformance (efficiency) was varied based on required $I_{s p}$ by the function: Efficiency $=\left(\mathrm{bb} * \mathrm{I}_{\mathrm{sp}}{ }^{2}\right) /\left(\mathrm{I}_{\mathrm{sp}}{ }^{2}+\mathrm{dd}^{2}\right)$ where $\mathrm{bb}=.764693$ and $\mathrm{dd}=2195.36$. This fit is representative of $8 \mathrm{~cm}$ test data. Masses for the thruster and components include gimbal, structure and thermal control masses. A spare PPU was assumed to ensure that two are operational so that roll control can be provided by the ion thrusters during thrusting. A digital control interface unit [DCIU] is added to control the thrusters, PPUs, and the feed system. The DCIU interfaces with the spacecraft computer. The Stirling system technology is based upon nickel-based super alloys and temperatures of 923K.

Shown in Table 1 are the system assumptions for the outer planetary target orbiters. The housekeeping power was limited to $60 \mathrm{~W}$ during thrusting. Spacecraft communications were restricted to ion thruster off-times when more power is available. Two thruster operation is assumed where possible to allow for attitude control of the spacecraft during cruise with the ion thrusters. Eight thrusters were carried on the spacecraft. Seven of the eight thrusters are expected to handle the required fuel throughput in case of engine-out.

\section{$\underline{\text { Mission Analyses }}$}

In order to assess REP's viability for outer planet missions the trajectory optimization code VARITOP (developed by Carl Sauer of JPL) was used to assess actual trajectories. ${ }^{19}$ The VARITOP code can also be used to optimize Isp and power level given the appropriate thruster and mass models. Specific launch vehicle performance can also be input to the code and optimal excess velocities found. For this analysis an Atlas V 551 medium launch vehicle was assumed using a Star 48 upper stage. ${ }^{20}$ Such a vehicle is capable of providing up to $400 \mathrm{~kg}$ launch mass to an excess velocity of $14.14 \mathrm{~km} / \mathrm{s}$ $\left(\mathrm{C} 3=200 \mathrm{~km}^{2} / \mathrm{s}^{2}\right)$.

\section{Outer Planetary Targets with REP}

The set of possible outer planetary targets is large. The set includes the outer planets (Jupiter, Saturn, Uranus, Neptune, Pluto), the outer planets' many moons (over 30 in all), as well as the many other objects not in orbit about the outer planets: Trojans, Centaurs, TransNeptunian Objects, Kuiper Objects, and various asteroids and comets (fig 6.). ${ }^{21}$ In order to 
simplify the analyses only the outer four planets were targeted. The resulting trip times and payloads found to get to these planets is representative of the times and payloads to the other objects in the vicinity. An additional spiral-in time will be needed to reach the outer planet's moons. This time was estimated using the Edelbaum-Fimple closed form method. ${ }^{19}$ No significant extra time is needed to reach the nonplanetary objects since their masses are so low.

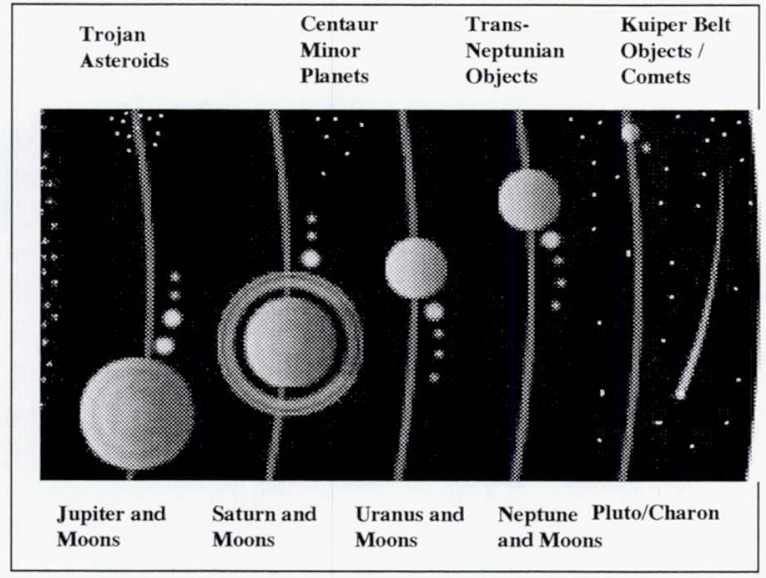

Figure 6. Potential Outer Planetary Targets

After finding several trajectories where the REP spacecraft provided all the interplanetary $\Delta \mathrm{V}$ for the mission (and getting very long trip times - as much as 24 years for Pluto) a new approach was taken. Since the REP propulsion and power systems have a relatively high specific mass it may not be reasonable for the REP to perform the whole mission of escape from Earth, accelerate out to and decelerate into the target. The REP spacecraft is, however, fairly small since a reasonable power level for an REP spacecraft is less than $1 \mathrm{~kW}$. Thus it was reasoned that a larger launch vehicle could perform the earth escape and the entire acceleration portion of the mission while the REP system would only perform the deceleration and near-body propulsion. (Past authors did note that using chemical stages in low Earth orbit did reduce the spiral out time but never took this extreme step of using very high excess velocities, medium class launch vehicles and relegating the REP to braking duties only.) ${ }^{4}$ This approach, in fact, turned out to be a good match, and once these new converged trajectories were found with VARITOP, the REP trip times to outer planetary targets were determined to be half of those of earlier runs.

Thus the optimal trajectory for using REP for an outer planetary orbiter consisted of a high excess velocity launch by a medium class launch vehicle (in this case the Atlas 551/Star 48) and the REP system beginning deceleration a few years after launch. Compared to the REP for flyby missions this used the launch vehicle and the REP much more efficiently; using REP to accelerate away from the Sun incurs high gravity losses, while using REP to decelerate is more and more efficient as the spacecraft travels further from the Sun. (In some higher power density [W / kg initial mass] cases a short acceleration period was provided by the REP system for a relatively short period $[\sim 10 \%$ of trip time] just after launch. )

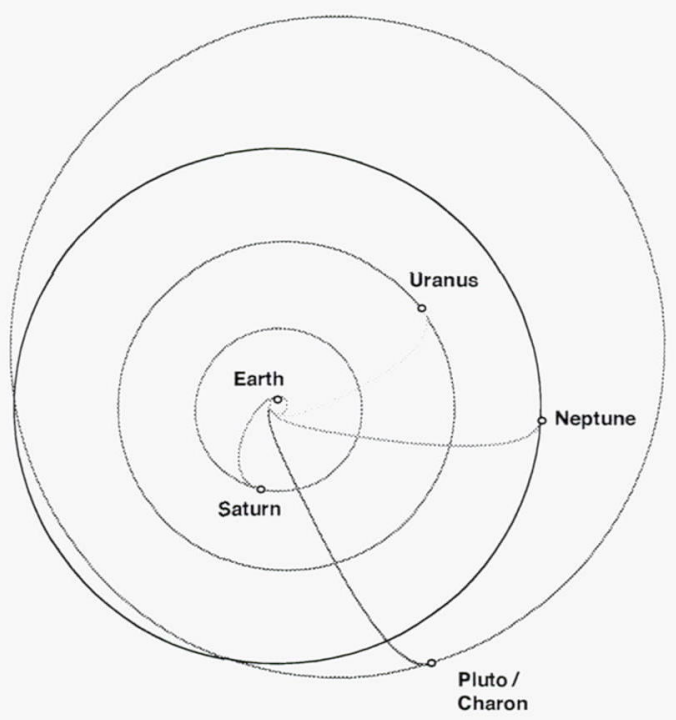

Figure 7. Direct REP Trajectories

The trajectories found for the various outer planetary distances (noted by Saturn, Uranus, Neptune, and Pluto) are shown in figure 7. Note that the trajectories provide almost straight paths to the target with a circularization at the end. It should be noted that no third body effects are used by VARITOP to determine these results. Thus the mass of the planet has no impact of the trajectory and no flybys with gravity assists are used. This greatly simplifies the trajectory and reduces launch window constraints. 


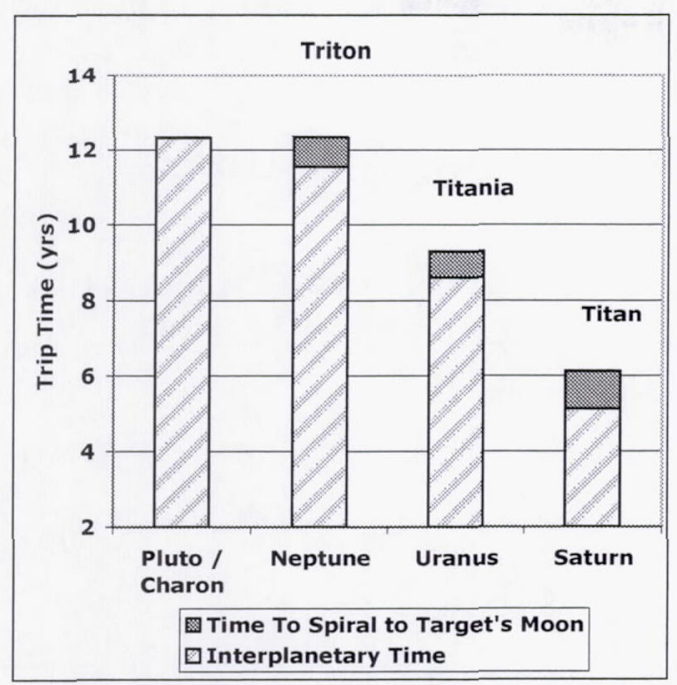

Figure 8. Orbiter Trip Time vs. Object [127 kg BSM]

Initial results are shown in figure 8 for the lightest spacecraft bus, science, and margin (BSM) currently conceived. For the BSM of 127 $\mathrm{kg}$ the trip times to the outer planetary targets are surprisingly quick with Pluto distance targets being close to 12 years from launch. Since the moons of the outer planets are also of great scientific interest an estimate of the time to spiral down from the high capture orbit (somewhere below the sphere of influence) was made for sample moons of the outer planets: Titan (Saturn), Titania (Uranus), and Triton (Neptune).

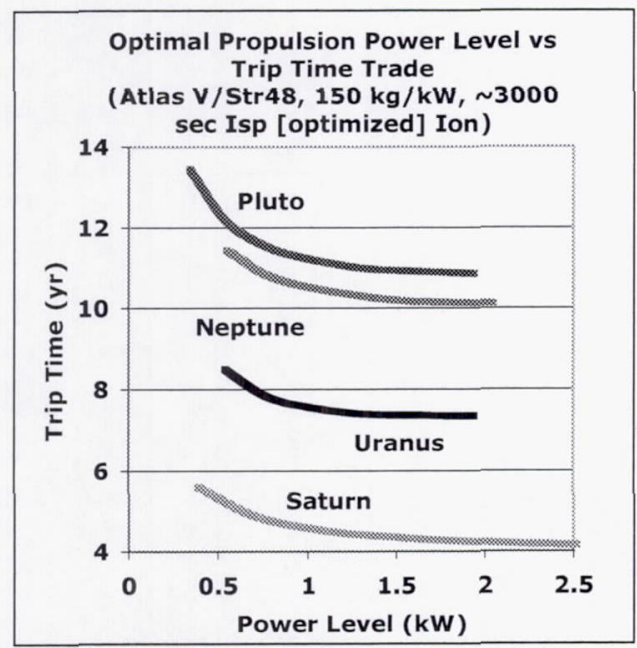

Figure 9. Power Level Trade

Results (also shown in figure 8) showed that the trip times were on the order of a year for all but Charon which was less than a month. This is due to the very low mass of the Pluto/Charon system.
The study varied several parameters to answer several specific questions. The first question was "what is the most appropriate power level for this mix of technology and launch vehicle?'. Figure 9 compares various power levels for the 2011 launch. It is evident that increasing powers from $300 \mathrm{~W}$ up to about $750 \mathrm{~W}$ notably reduces the trip times for the outer planet missions. Adding power past that provides little benefit. Thus the 'knee' of the curve was assumed to be $\sim 750 \mathrm{~W}$ and the rest of the analyses used this power level.

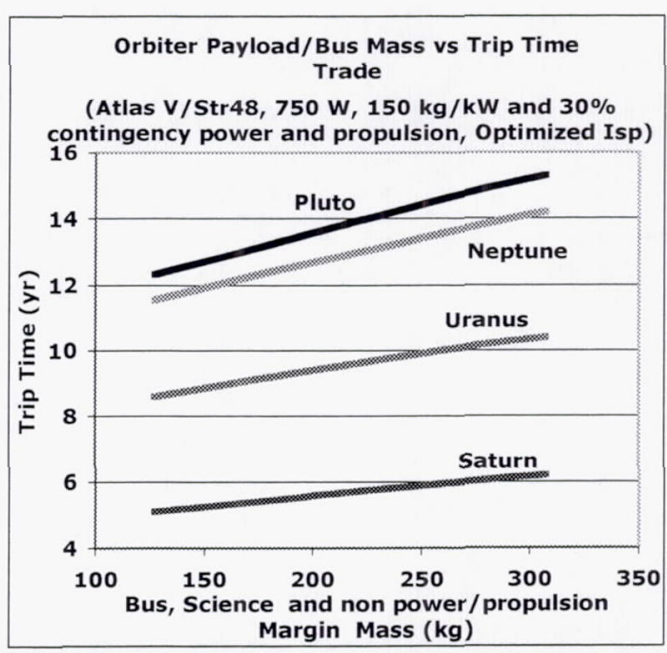

Figure 10. BSM Mass vs. Trip Time Trade

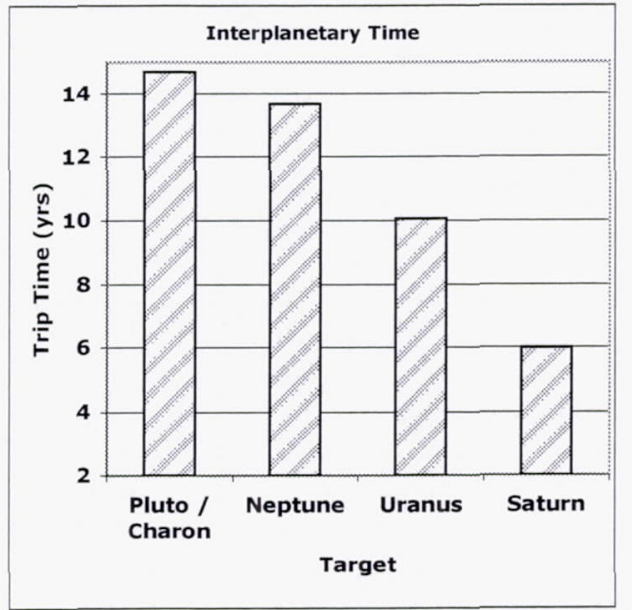

Figure 11. Orbiter Trip Time vs. Object [267 kg BSM]

The next question was how trip time would increase with heavier BSM masses. Figure 10 shows the variation in spacecraft mass versus trip time. Each curve shows this variation for a different planetary distance. As expected, as the BSM masses are increased the trip time is extended. However, as shown by figure 11 the BSM may be more than doubled to $267 \mathrm{~kg}$ with 
only an increase of around $17 \%$ in trip time. (spiral in time have estimates not yet made.)

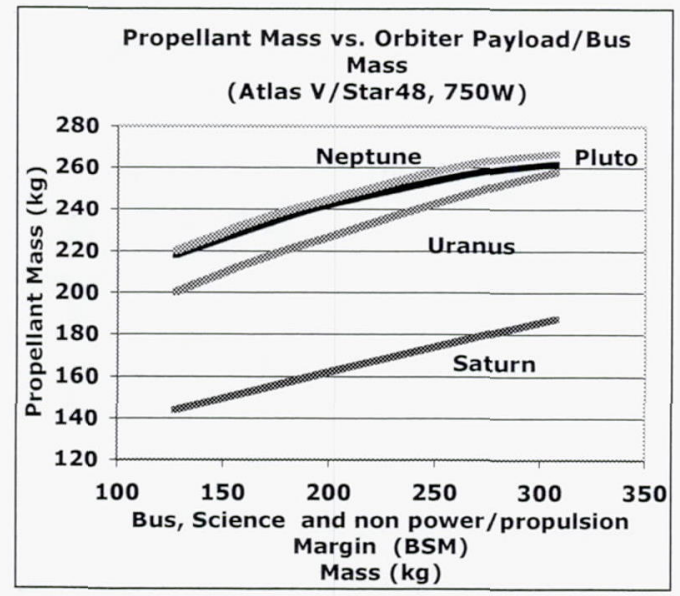

Figure 12. Propellant Mass Requirements

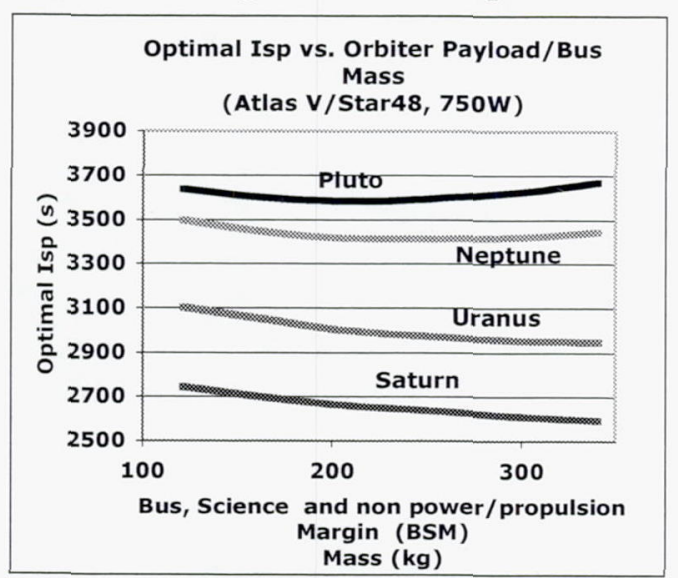

Figure 13. Single Setp-point Optimal Isp vs. Target and BSM

The required propellant throughputs and optimal $\mathrm{I}_{\mathrm{sp}} \mathrm{S}$ were also found in each analysis. These parameters are key to guiding the propulsion technology development. Figures 12 and 13 show the variation, respectively. It is clear that further targets require more throughput per thruster or more engines. The baseline included eight engines with three power processors (two engine operation). For most of the mission cases the engine throughput is around $30 \mathrm{~kg}$ /engine. In the case of engine out ( only 7 engines available) around $35 \mathrm{~kg}$ throughput on each engine would be required for the heavier BSM masses. This equates to required burn times of three to four years for each engine. The GRC developed NSTAR $30 \mathrm{~cm}$ thruster, with which the $8-\mathrm{cm}$ ion thruster draws heritage, has currently been tested for almost three years in a ground-based life test. The optimal, single set- point Isps were determined by VARITOP to be in the $2600 \mathrm{sec}$ to $3700 \mathrm{sec}$ range which is commensurate with the $8 \mathrm{~cm}$ ion engines current design as shown in figure 13. A summary of the $750 \mathrm{~W}$ REP cases is shown in Table 2.

Table 2. Summary of $750 \mathrm{~W}$ Cases [Atlas 551/Star 48, 2011 Launch]

\begin{tabular}{|c|c|c|c|c|c|}
\hline $\begin{array}{l}\text { Bus. Science, and non } \\
\text { power/propulsion } \\
\text { margins (kg) [common } \\
\text { to all targets] } \\
\text { Power \& Propulsion } \\
\text { System Contingency } \\
\text { (kg) ( } 30 \% \text { of } 750 \mathrm{~W} \\
\text { Power \&Propulsion } \\
\text { system) [common to all } \\
\text { targets] }\end{array}$ & 127 & 167 & 207 & 267 & 307 \\
\hline \multicolumn{6}{|l|}{ Saturn and Vicinity } \\
\hline Launch C3 $\left(\mathrm{km}^{2} / \mathrm{s}^{2}\right)$ & 175 & 169 & 162 & 154 & 149 \\
\hline $\begin{array}{l}\text { Launch Mass (kg) } \\
\text { Power \& Propulsion }\end{array}$ & 431 & 483 & 533 & 610 & 660 \\
\hline System Dry Mass (kg) & 126 & 128 & 129 & 130 & 131 \\
\hline Propellant Mass (kg) & 144 & 154 & 164 & 178 & 188 \\
\hline Trip Time (yr) & 5.1 & 5.4 & 5.6 & 6.0 & 6.2 \\
\hline Optimal Isp (s) & 2702 & 2666 & 2644 & 2610 & 2594 \\
\hline REP $\triangle \mathrm{V}(\mathrm{km} / \mathrm{s})$ & 10.7 & 10.1 & 9.5 & 8.9 & 8.5 \\
\hline \multicolumn{6}{|l|}{ Uranus and Vicinity } \\
\hline Launch C3 $\left(\mathrm{km}^{2} / \mathrm{s}^{2}\right)$ & 167 & 160 & 154 & 146 & 141 \\
\hline $\begin{array}{l}\text { Launch Mass }(\mathrm{kg}) \\
\text { Power \& Propulsion }\end{array}$ & 494 & 552 & 606 & 686 & 737 \\
\hline System Dry Mass (kg) & 133 & 134 & 135 & 137 & 138 \\
\hline Propellant Mass (kg) & 200 & 216 & 229 & 248 & 258 \\
\hline Trip Time (yr) & 8.6 & 9.05 & 9.48 & 10.07 & 10.4 \\
\hline Optimal Isp (s) & 3057 & 3007 & 2981 & 2956 & 2953 \\
\hline REP $\triangle \mathrm{V}(\mathrm{km} / \mathrm{s})$ & 15.6 & 14.7 & 13.9 & 13 & 12.5 \\
\hline \multicolumn{6}{|l|}{ Neptune and Vicinity } \\
\hline Launch C3 $\left(\mathrm{km}^{2} / \mathrm{s}^{2}\right)$ & 164 & 158 & 152 & 145 & 140 \\
\hline $\begin{array}{l}\text { Launch Mass (kg) } \\
\text { Power \& Propulsion }\end{array}$ & 515 & 572 & 625 & 702 & 749 \\
\hline System Dry Mass (kg) & 135 & 136 & 137 & 139 & 139 \\
\hline Propellant Mass (kg) & 220 & 235 & 247 & 262 & 267 \\
\hline Trip Time (yr) & 11.6 & 12.2 & 12.8 & 13.7 & 14.2 \\
\hline Optimal Isp (s) & 3451 & 3418 & 3415 & 3423 & 3448 \\
\hline $\operatorname{REP} \Delta \mathrm{V}(\mathrm{km} / \mathrm{s})$ & 18.8 & 17.8 & 16.9 & 15.7 & 15 \\
\hline \multicolumn{6}{|l|}{$\begin{array}{l}\text { Pluto/ Charon and } \\
\text { Vicinity }\end{array}$} \\
\hline Launch $\mathrm{C} 3\left(\mathrm{~km}^{2} / \mathrm{s}^{2}\right)$ & 165 & 158 & 152 & 145 & 141 \\
\hline $\begin{array}{l}\text { Launch Mass (kg) } \\
\text { Power \& Propulsion }\end{array}$ & 513 & 569 & 622 & 696 & 743 \\
\hline System Dry Mass (kg) & 134 & 136 & 137 & 138 & 139 \\
\hline Propellant Mass (kg) & 218 & 232 & 244 & 257 & 262 \\
\hline Trip Time (yr) & 12.3 & 13.0 & 13.7 & 14.7 & 15.3 \\
\hline Optimal Isp (s) & 3602 & 3585 & 3588 & 3624 & 3668 \\
\hline $\operatorname{REP} \Delta \mathrm{V}(\mathrm{km} / \mathrm{s})$ & 19.5 & 18.5 & 17.5 & 16.3 & 15.7 \\
\hline
\end{tabular}




\section{Other Options to Outer Planetary Targets}

The REP outer planetary orbiter missions showed relatively fast transit times for small payloads. Other technologies can also reach the other planets and will now be compared to determine REP's role in outer planetary exploration.

Using only state-of-art chemical systems to capture at Jupiter, Saturn, Uranus and Neptune would require the largest of planned launch vehicles (e.g. Delta IV Heavy) and/or planetary flybys and equivalent trip times for each orbiter. Adding aerocapture systems can improve the delivered payload but requires technology development and imposes risk for the first mission to the planet. For Pluto/Charon or any of the other objects (Trojans, Centaurs, TransNeputnian Objects, Kuiper Objects, and various asteroids and comets) chemical capture requires much longer trip times and aerocapture is not possible

Combining aerocapture technologies with a solar electric propulsion (SEP) stage has shown better results. This concept uses an SEP stage and a Venus flyby to send a payload quickly to an outer planet where an aerocapture system captures into orbit about one of the large outer planets (Jupiter, Saturn, Uranus, or Neptune). The SEP system is separated before arriving at the target planet. Once captured in orbit small chemical maneuvers and time can allow transfers to a planet's moons with the appropriate planet/moon gravity flybys. The SEP / Aerocapture propulsion system can deliver respectable payload spacecraft $\sim 500 \mathrm{~kg}$ to these planets using medium launch vehicles and trip times similar to the REP system. Aerocapture at Pluto or the other above mentioned objects is not viable so the $\mathrm{SEP} / A$ erocapture method is not available.

The other approach currently of interest is nuclear electric propulsion (NEP). The NEP system carries a reactor with powers of 100 to $500 \mathrm{~kW}$. Since the spacecraft is fairly large $(>8000 \mathrm{~kg}$ ) the NEP vehicle must be launched with a heavy launch vehicle to a low earth orbit and spiral out. The NEP vehicle then accelerates out to and decelerates into an outer object.
Quick spiraling at the target is then possible. Payloads from $500 \mathrm{~kg}$ and up are possible with power available at the target of $>100 \mathrm{~kW}$. Trip times are similar to the REP system. The main difference is the size of the vehicle, payload and power level. The NEP system is more appropriate for flagship type missions with the REP being perhaps a cheaper solution for the emerging New Frontiers Class missions (similar to the Discovery Class). Thus the REP is perhaps more appropriate for smaller targets with more focused science.

\section{Further Work}

The analyses performed so far show great promise for the use of REP for small outer planetary missions. Future analysis work will concentrate on two areas: spacecraft point designs and specific target evaluations. Spacecraft point designs will be made to obtain a better idea of the potential mass all the subsystems as well as the impact of other launch systems. In addition, more specific targets will be evaluated, especially those objects not close to the large outer planets.

\section{$\underline{\text { Conclusions }}$}

Studies were undertaken to further show what a radioisotope electric propulsion system would look like and what it could do for outer planetary exploration. On-going work in small ion thrusters, Stirling radioisotope power systems, and small planetary science spacecraft point toward the possibility of a viable REP spacecraft for outer planetary exploration. Besides the outer planets and their moons the REP system can allow equally quick missions to other outer planetary objects such as the Trojans, Centaurs, Trans-Neputnian Objects, Kuiper Objects, and various asteroids and comets. A new direct trajectory was found to allow these relatively fast trip times for a new small class of outer planetary orbiters for the New Frontiers Class missions. 


\section{$\underline{\text { References }}$}

[1] Oleson, S.R., Gefert, L., Patterson, M., Schreiber, J., Benson, S., McAdams, J., Ostdiek, P., "Outer Planet Exploration with Advanced Radioisotope Electric Propulsion", IEPC-20010179, International Electric Propulsion Conference, Pasadena, CA, October, 2001.

[2] Oleson, S.R., Gefert,, L., Schreiber, J., McAdams, J., "Sub-Kilowatt Radioisotope Electric Propulsion for Outer Solar System Exploration", Forum on Innovative Approaches to Outer Planetary Exploration 2001-2020, Lunar and Planetary Institute, Houston Texas, Feb, 2001.

[3] Noble, R.J., "Radioisotope Electric Propulsion of Small Payloads for Regular Access to Deep Space", AIAA 93-1897, 29 th $^{\text {th }}$ Joint Propulsion Conference, Monterey, CA, 1993.

[4] Noble, R.J., "Radioisotope Electric Propulsion for Small Robotic Space Probes, J. British Interplanetary Society, Vol 49, pp. 455468, 1996.

[5] Noble, R. J., " Radioisotope Electric Propulsion of Sciencecraft to the Outer Solar System and Near-Interstellar Space", Nuclear News, Nov. 1999, pp 34-40.

[6] Patterson, M.J., "Low-Power Ion Thruster Development Status," AIAA Paper No. 98-3347, July 1998

[7] Foster, J.E. and Patterson, M.J, "Enhanced Discharge Performance in a Ring Cusp Plasma Source," IEPC Paper No. 99-159, October 1999. Also NASA TM-2000-209765.

[8] Menart, J.A. and Patterson, M.J., "Magnetic Circuit for Enhanced Discharge Chamber Performance of a Small Ion Thruster," AIAA Paper No. 98-3343, July 1998.

[9] Patterson, M.J. and Grisnik, S.P., "Scaling of Ion Thrusters to Low Power," IEPC Paper No. 97-098, August 1997. Also NASA TM-1998206530.

[10] Pinero, L.R., Patterson, M.J., and Bowers, G.E., "Development of Power Electronics for a 0.2kW-Class Ion Thruster," IEPC Paper No. 97 099, August 1997.
[11] Pinero, L.R., Bowers, G.E., and Lafontaine, E.M., "Development Status of a Power Processing Unit for Low Power Ion Thrusters," AIAA Paper No. 2000-3817, July 2000.

[12] Pinero, L.R., and Bowers, G.E., "Subkilowatt Power Processing Unit with an $8-\mathrm{cm}$ Ion Thruster," Paper No. IEPC-01-331. Proposed for presentation at the International Electric Propulsion Conference, October 2001.

[13] Meckel, N., "Design Concept for a Low Power Ion Propulsion System", Paper No. IEPC01-108. Proposed for presentation at the International Electric Propulsion Conference, October 2001.

[14] Haag, T., Soulas, G., "Performance of $8 \mathrm{~cm}$ Pyrolytic- graphite Ion Thruster Optics", AIAA2002-4335, $38^{\text {th }}$ Joint Propulsion Conference, Indianpolis, Indiana, July, 2002.

[ 15 ] Furlong, R., and Shaltens, R.K., "Technology Assessment of DOE's 55-We Stirling Technology Demonstrator Convertor (TDC)," NASA TM-2000-210509, Proceedings, $35^{\text {th }}$ Intersociety Energy Conversion Engineering Conference, Las Vegas, NV.

[16] Surampudi, R., Carpenter, R., El-Genk, M., Herrera, L.,Mason, L.S., Mondt, J., Nesmith, B., Rapp, D., Wiley, R., "Advanced Radioisotope Power Systems Report".

[17] Thieme, L.G. and Schreiber, J.G., "Update on the NASA GRC Stirling Technology Development Project," 2000, NASA TM-2000210592, Proceedings, 2001 Space Technology Applications International Forum, M.El-Genk editor, Albuquerque, NM.

[18] Factsheet, "New Horizons: Shedding Light on New Frontiers", hetr:/wluto buad edu.

[19] Sauer, C., "A Users Guide to VARITOP: A General Purpose Low-Thrust Trajectory Optimization Program", Advanced Projects Group, Jet Propulsion Laboratory, Nov. 1991.

[20] Atlas Launch System Planner's Guide, Rev. 9, Sept. 2001, International Launch Systems

[21] Weissman, P.R., et al, "Encyclopedia of the Solar System", Academic Press, 1999. 
Public reporting burden for this collection of information is estimated to average 1 hour per response, including the time for reviewing instructions, searching existing data sources, gathering and maintaining the data needed, and completing and reviewing the collection of information. Send comments regarding this burden estimate or any other aspect of this Davis Highway, Suite 1204, Arlington, VA 22202-4302, and to the Office of Management and Budget, Paperwork Reduction Project (0704-0188), Washington, DC 20503.

\begin{tabular}{|l|l|l}
\hline 1. AGENCY USE ONLY (Leave blank) & $\begin{array}{r}\text { 2. REPORT DATE } \\
\text { September } 2002\end{array}$ & $\begin{array}{r}\text { 3. REPORT TYPE AND DATES COVERED } \\
\text { Technical Memorandum }\end{array}$ \\
\hline
\end{tabular}

4. TITLE AND SUBTITLE

Radioisotope Electric Propulsion for Fast Outer Planetary Orbiters

6. AUTHOR(S)

Steven Oleson, Scott Benson, Leon Gefert, Michael Patterson, and Jeffrey Schreiber

7. PERFORMING ORGANIZATION NAME(S) AND ADDRESS(ES)

National Aeronautics and Space Administration John H. Glenn Research Center at Lewis Field Cleveland, Ohio 44135-3191

9. SPONSORING/MONITORING AGENCY NAME(S) AND ADDRESS(ES)

National Aeronautics and Space Administration

Washington, DC 20546-0001
5. FUNDING NUMBERS

$$
\text { WU-344-96-8D-00 }
$$

8. PERFORMING ORGANIZATION REPORT NUMBER

E-13575

10. SPONSORING/MONITORING AGENCY REPORT NUMBER

NASA TM-2002-211893

AIAA-2002-3967

\section{SUPPLEMENTARY NOTES}

Prepared for the 38th Joint Propulsion Conference and Exhibit cosponsored by the AIAA, ASME, SAE, and ASEE, Indianapolis, Indiana, July 7-10, 2002. Responsible person, Steven Oleson, organization code 6910, 216-977-7426.

12a. DISTRIBUTION/AVAILABILITY STATEMENT 12b. DISTRIBUTION CODE

Unclassified - Unlimited

Subject Categories: 13, 20, and 91

Distribution: Nonstandard

Available electronically at http://gltrs.grc.nasa.gov

This publication is available from the NASA Center for AeroSpace Information, 301-621-0390.

13. ABSTRACT (Maximum 200 words)

Recent interest in outer planetary targets by the Office of Space Science has spurred the search for technology options to enable relatively quick missions to outer planetary targets. Several options are being explored including solar electric propelled stages combined with aerocapture at the target and nuclear electric propulsion. Another option uses radioisotope powered electric thrusters to reach the outer planets. Past work looked at using this technology to provide faster flybys. A better use for this technology is for outer planet orbiters. Combined with medium class launch vehicles and a new direct trajectory these small, sub-kilowatt ion thrusters and Stirling radioisotope generators were found to allow missions as fast as 5 to 12 years for objects from Saturn to Pluto, respectively. Key to the development is light spacecraft and science payload technologies.

\section{SUBJECT TERMS}

Electric propulsion; Radioisotope power; Direct outer planet trajectories

17. SECURITY CLASSIFICATION
OF REPORT
Unclassified

18. SECURITY CLASSIFICATION
OF THIS PAGE
Unclassified

Unclassified

19. SECURITY CLASSIFICATION
OF ABSTRACT
Unclassified

20. LIMITATION OF ABSTRACT

NSN 7540-01-280-5500 